\title{
Sustainability of Italian wines: Knowledge, understanding, and interest of consumers
}

\author{
Danielle Borra, Andrea Viberti, Stefano Massaglia ${ }^{\mathrm{a}}$, and Andrea Dal Vecchio \\ Università di Torino, DISAFA, Largo Paolo Braccini, 2, 10095 Grugliasco (TO), Italia
}

\begin{abstract}
The continuous consumption of resources and the progressive climatic changes have contributed to develop a new range of products with a "greener" vocation. After the shift to organic and biodynamic production, companies have started to promote products' sustainability. The wine sector has undergone a transformation connected with the emergence of several projects related to the concept of sustainability. But what the consumer knows and thinks of all this? In this regard, it was carried out a study about the perception of the consumer on issues related to sustainability. The goals are multiple: to define the concept of sustainability perceived by consumers, to evaluate the spread of eco-friendly products, to measure the interest and willingness in spending on these products and finally to assess the knowledge of the main brands that identify some sustainable projects. Thanks to this first part that fits into a larger study still in progress, it was possible to obtain an initial assessment of the motivations that influence the purchase of wine, learn more about the consumer on these issues and assess the prevalence of brands associated with each of these major projects on the Italian scene.
\end{abstract}

\section{Introduction}

The continuous consumption of resources and the advent of a slow but progressive change in the climate have contributed to the development, in some of the consumers, of a growing awareness of environmental issues. Thanks to this new demand, a new range of products with a vocation more and more green has gradually developed. In this regard, by following the shift towards organic production, we can see a gradual proliferation of various projects related to the concept of sustainability that are involving an increasing number of companies. The name "Green Marketing" identifies a version of the ecosustainable traditional marketing, whose main purpose is to spread innovative choices that support the environment. The Green Marketing developed something revolutionary, which aims to the reduction of environmental impact of products. The company that uses the Green Marketing in fact, seeks to create products and services more environmentally friendly than its competitors trying to affirm its superiority in the management of environmental sustainability. In addition, to preserve the environment and to differentiate itself from competitors, clients are trained to recognize and enhance its eco-friendly products. There are several types of brands in the wine sector interested in new practices related to organic and biodynamic certifications.

At the same time, various forms of "sustainability" were developed in order to give, in various market branches, an added value to the companies as well as multiple benefits to the consumer.

\footnotetext{
${ }^{a}$ Corresponding author: stefano.massaglia@unito.it
}

A survey carried out in Italy in 2013 proves that, of about 2,340 people surveyed from various backgrounds all residents in Italy, in $54 \%$ of cases is indicated that sustainability is a condition for wines naturalness, $40 \%$ thinks that it is related to security.

Given these data, it was decided to carry out a study whose objectives are: to define the concept of sustainability perceived by consumers, to evaluate the spread of ecofriendly products, to measure the interest and willingness of spending on these products, and to assess the knowledge of the main sustainable brands.

\section{Material and methods}

In order to obtain the opinion of the consumer, guided interviews were drafted and completed during events, exhibitions, food and wine fairs as well as online with an online questionnaire. It consists of an initial part focused on the characterization of the consumer with information about the age, origin, habits of consumption, the level of involvement in the wine sector; a second part was related to the definition of eco-friendly products and organic foods, with two open-ended questions where the consumer was asked to try to define the concept of sustainable wine and organic wine. In the third part, more attention was given to the characteristics they look for when purchasing wine. Another section of the questionnaire evaluated the knowledge of some of the biggest sustainable brands on the Italian market. The final questions of the questionnaire concerned instead the purchase of environmentally friendly wines and the eventual willingness to pay a higher amount for them. 


\section{Data analysis}

With a total of 203, the interviews involved a sample of people resident in Italy of which $61 \%$ were men and $39 \%$ women. $10 \%$ of the sample consumes wine only on special occasions, $30 \%$ drinks wine 2-3 times a month, $40 \%$ from 1 to 3 times a week, the remaining $20 \%$ drinks it regularly. From these data, it is clear that $60 \%$ of respondents consume wine one or more times a week and the majority have a good familiarity with wine. These statements are confirmed by the analysis of the questions related to the motivations that lead to an interest in wine. $51 \%$ of the respondents say they have participated or would be interested in participating in wine tasting courses; $30 \%$ say they practice enotourism to discover the wines directly from producers in the areas of production, while $12 \%$ say they work in the wine sector. $65 \%$ of the sample buys wine directly from the producer, $47 \%$ from supermarkets, and $43 \%$ from wineries. Direct selling represents a good source of income for companies: by relying on direct contact with the consumer, winemakers can promote their activities and oenological products themselves encouraging the customer loyalty.

117 comments were given to the open-ended question in order to define the concept of sustainable wine. Most of them describe sustainable practices as an attempt to reduce the use of chemicals, and to pay more attention to the environment. In approximately $5 \%$ of comments, consumers said they have no idea of the meaning, while in only $2.5 \%$ of cases, the definition was in depth and clear. 6 different characteristics related to the concept of sustainability were listed by asking consumers to indicate what or which in their opinion would define that concept. The highest number of preferences $(80 \%)$ was collected by the use of smaller quantities of chemicals in the field. This trend underlines how consumers perceive the use of chemicals as a negative factor preferring products obtained with less impact practices and more tied to tradition and to the naturalness of the products. In second place, chosen by $61 \%$ of consumers, we find the use of energy coming from renewable sources. Great importance is given by the consumer to all the stages, from vines to shops. In third place, $56 \%$ voted for the reduction in the use of packaging materials. This step is a critical parameter for the wine sector. Glass continues to be much preferred both by consumers and producers. The use of glass leads to very high weights and to the need of strong packaging in order to protect the bottles from breaking. 55\% of the sample voted for better management of sewage and water, which should not be wasted. In fifth place, with $43 \%$ voted for the reduction of the use of sulfites. Very often the use of sulfites is recognized by consumers as a negative factor when purchasing. At the end, the focus on recruitment and human resources that is indicated by $36 \%$ of the sample. When we asked to describe the concept of organic wine, the comments recorded were 129, 12 had almost the same definition of sustainability. The majority of consumers stated that organic wine is produced without use of chemicals, pesticides and treatment in general. In at least 5 cases this definition is also associated with a reduction of sulfites contents. Organic wine is seen above all as a product made with natural practices.
Table 1. Attributes' mean scores.

\begin{tabular}{lccc}
\hline & Mean & SD & CV \\
\hline Quality & 4.76 & 0.22 & 0.05 \\
Area of origin & 4.16 & 0.47 & 0.11 \\
Naturalness & 3.98 & 0.48 & 0.12 \\
Producer & 3.89 & 0.45 & 0.12 \\
Price & 3.56 & 0.44 & 0.12 \\
Suggested & 3.50 & 0.48 & 0.14 \\
Sustainability & 3.45 & 0.57 & 0.17 \\
Low content of sulfites & 3.42 & 0.64 & 0.19 \\
Food pairing & 3.33 & 0.58 & 0.17 \\
Organic practices & 3.13 & 0.62 & 0.20 \\
Brand awareness & 3.00 & 0.55 & 0.18 \\
Biodynamic practices & 2.72 & 0.67 & 0.25 \\
Guides reviews & 2.64 & 0.62 & 0.23 \\
On-line reviews & 2.59 & 0.63 & 0.25 \\
\hline
\end{tabular}

Consumption habits vary from person to person depending on the knowledge and sensitivity to the issues raised. $29 \%$ says they buy wine that comes from organic grapes, $11 \%$ buys products made according to biodynamic parameters. $32 \%$ purchase sustainable products. The concept of sustainability, not clearly defined yet in the consumer's opinions, appears to be the one that wins among the largest number of consumers. Even organic product results to be quite popular with consumers. Significantly lower the purchase of biodynamic products which is targeted by fewer people.

In the next step, several of the main attributes [1-3] able to influence the consumer at the time of purchase were selected. Other attributes referring to wine sustainability were added to the first ones and submitted to the respondents. Respondents were asked to give a score in a Likert scale from 1 (not important at all) to 5 (very important) to each attribute. In table 1 are reported the 14 selected attributes with the mean scores, standard deviations and coefficients of variation.

The highest score was attributed to quality with 4.76 points. Although quality is a factor that can assume different facets from consumer to consumer the scores expressed by the sample are concentrated mainly in the maximum level of 5 points with $78 \%$, followed by $20 \%$ with a score of 4 , and then $2 \%$ of 3 .

The second highest score (4.16) refers to the attribute area of origin. Depending on the area of production, climate, soil, grape varieties and, consequently, the wines produced change as well as the perception of the level of quality that the consumer owns. A wine from well known areas is often preferred to one from a lesser known one. Also in this case we can appreciate a high concentration of responses $(80 \%)$. The territory of origin influences a lot the choice when buying.

After those two parameters the generic attribute naturalness ranked third with a score close to 4 points. This concept can hardly be explained with a clear definition. To understand the perception, the concept given was about the of naturalness of a product obtained with the least number of external interventions in order to preserve what nature has to offer. $34 \%$ of the sample indicates a score of 5, 39\% a score of $4,20 \%$ a score of 3 , followed $5 \%$ to $2,2 \%$, equal to one. 
Fourth comes the attribute producer. The winemaker, if known and appreciated is synonym of the quality of the product. Nevertheless, this factor appears to be slightly less influential than the previous. Only $29 \%$ indicates the maximum score of $5,37 \%$ a score of $4,28 \%$ a score of 3 and $6 \%$ a score of 2 .

Price ranks fifth and does not seem to be a predominant factor in the choice of wine to buy. In this regard, only $12 \%$ gave a score of $5,42 \%$ a score of $4,37 \%$ a score of $3,8 \%$ a score of 2 , and then $2 \%$ a score of 1 . This data permits to argue that the sample of consumers cares more about the product itself rather than its price. As long as there are other parameters ensuring consumers wine quality, most of the buyers do not care about the price. Friends' or pairs' references obtain the sixth score (3.50 points). The generic attribute sustainability ranks just seventh and reaches a score (3.42 points) quite similar to the one reached by the attribute low levels of sulfites. The latter attribute is ascribable to sustainable winemaking techniques.

The other two attributes directly referring to sustainability, organic (3.13 points) and biodynamic practices (2.72), rank tenth and twelfth, although one third of the sample declares to consumes organic foods. In the end of the questionnaire the knowledge of four of the most well known sustainable wine brands was evaluated. Vinolibero is a brand set up by a consortium of companies with the aim of using more natural products to ensure the health of the consumer, as well as a lower environmental impact in order to reduce resource consumption. Magis is the brand introduced by Bayer which distinguishes the companies under the supervision of DNV and of the pharmaceutical company which have decided to follow a protocol that enables a reduction in environmental impact. ViniVeri, other association includes a number of companies that have decided to produce a organic and biodynamic wine which is as much as possible environmentally friendly. Finally, the most recently established and presented by the Italian Ministry of Environment at Vinitaly 2014 called VIVA. Thanks to its study on all activities involving the cultivation of wine grapes until its commercialization, it was possible to develop all the parameters that allow a certification about the sustainability of the companies.
The most well known brand results to be VinoLibero ( $40 \%$ of the sample). This result is certainly due to advertising campaigns that involved television and radio networks, the national press and to the presence of the products in retail chains associated by the consumers to a high levels of quality. The second place goes to ViniVeri selected by $18 \%$, followed by the label VIVA with $13 \%$ and at the end Magis project with $11 \%$.

The commitment to sustainable production in the wine market could guarantee a good investment, not only for reducing the impact on the ecosystem and the health of consumers, but also in economic terms. Infact $87 \%$ of the sample affirms that is ready to spend more if the product is eco-friendly. Of these, $17 \%$ would spend up to $5 \%$ more, $38 \%$ from $6 \%$ to $10 \%$ more, $28 \%$ from $11 \%$ to $15 \%$ more than $13 \% 16-20 \%$ more and 4 more than $20 \% .72 \%$ of the sample also believes that sustainable wines may represent the future.

\section{Conclusions}

Wines' sustainability has a great appeal on Italian consumers, although they don't seems to have a wide knowledge of the implications of the application of this concept to vine growing and wine making techniques. Sustainability attributes, at the moment, don't seem to have a predominant influence on consumer wine choice, but the growing attractiveness showed by sustainability on Italian wine consumers will bring more and more winemakers to produce more sustainable wines and wine marketers to use sustainability attributes in order to create competitive advantages.

\section{References}

[1] J. M. Gil, M. Sánchez., Brit. Food J. 99.1, 3-11 (1997)

[2] L. Casini, R. Cam, A. M. Corsi, Journal of Wine Research 20.2, 125-142 (2009)

[3] M. Corduas , L. Cinquanta, C. Ievoli, Food Qual. Prefer, 28.2. 407-418 (2013) 